\title{
The role of early life variables on the risk of fractures from birth to early adolescence: a prospective birth cohort study
}

\author{
P. C. Hallal • F. V. Siqueira • A. M. B. Menezes • \\ C. L. P. Araújo • S. A. Norris • C. G. Victora
}

Received: 7 December 2008 / Accepted: 26 January 2009/Published online: 7 March 2009

(C) The Author(s) 2009. This article is published with open access at Springerlink.com

\begin{abstract}
Summary In a prospective cohort from Brazil, we evaluated the incidence of fractures from birth to early adolescence and examined risk factors for fractures. The incidence was $14.2 \%$ (95\%CI 13.2, 15.2). Male sex, birth length, and maternal age at delivery were positively associated with the risk of fractures. Introduction This study aims to evaluate the incidence of fractures from birth to 11 years of age and to explore the effect of early life variables on the risk of fractures.
\end{abstract}

P. C. Hallal $(\bowtie) \cdot$ A. M. B. Menezes $\cdot$ C. L. P. Araújo •

C. G. Victora

Post-graduate Program in Epidemiology,

Federal University of Pelotas,

Rua Marechal Deodoro 1160,

ZIP: 96030-002 Pelotas, Brazil

e-mail: prchallal@terra.com.br

A. M. B. Menezes

e-mail: anamene@terra.com.br

C. L. P. Araújo

e-mail: cora.araujo@terra.com.br

C. G. Victora

e-mail: cvictora@terra.com.br

P. C. Hallal

Post-graduate Program in Physical Education,

Federal University of Pelotas,

Pelotas, Brazil

\section{F. V. Siqueira}

School of Physiotherapy, Catholic University of Pelotas,

Pelotas, Brazil

e-mail: fcvsiqueira@uol.com.br

\section{S. A. Norris}

Department of Paediatrics, MRC Mineral Metabolism

Research Unit, University of the Witwatersrand,

Johannesburg, South Africa

e-mail: san@global.co.za
Methods All children $(N=5,249)$ born in 1993 in the city of Pelotas, Brazil were enrolled in a prospective birth cohort study. In 2004-2005, 87.5\% of the cohort members were sought for a follow-up visit. History of fractures, including anatomic site and age of the fracture were asked to mothers.

Results The incidence of fractures from birth to 11 years of age was $14.2 \%(95 \% \mathrm{CI} 13.2,15.2)$. Out of the 628 subjects who experienced a fracture, 91 reported two and only 20 reported three or more fractures. Male sex, birth length, and maternal age at delivery were positively associated with the risk of fractures. No consistent associations were found for family income, maternal body mass index, smoking during pregnancy, and birth weight.

Conclusions Birth length seems to have long-term effect on musculoskeletal health. The higher risk of fractures among children of older mothers needs to be confirmed by other studies. In accordance to the developmental origins of diseases, fractures seem to be, at least in part, programmed in early life.

Keywords Epidemiology · Fractures .

Musculoskeletal disorders · Prospective studies

\section{Introduction}

Childhood and adolescent fractures are a public health concern. One of every two children will break at least one bone between birth and late adolescence [1], making fractures the most frequent injury causing hospitalization during childhood [2]. Fractures in children may cause a series of long-term harmful consequences for health, including secondary osteoarthritis, alignment problems of the fractured bone, and acute compartment syndrome [3, 4]. 
Most studies on fractures investigate older adults, mainly due to the high burden of osteoporotic disease. However, the incidence of fractures in childhood and adolescence is as high as in the elderly [5-7], and studies in young subjects are needed for a better understanding of the determinants of fractures [8].

A cohort study from New Zealand showed that childhood and adolescent fractures were associated with early life exposures, including birth length, weight, and height at age 3 years and from 5 to 18 years [8]. The ideal design for evaluating the impact of early life exposures on fracture risk is a prospective study in which subjects are followedup from birth to adulthood. Such studies are rare, particularly in low and middle-income settings [9]. We explored the effect of early life variables, such household socioeconomic status, maternal characteristics, birth outcomes, and gender, on the risk of fractures from birth to early adolescence in a prospective cohort study carried out in Brazil.

\section{Materials and methods}

All hospital-delivered children born in 1993 in the city of Pelotas were enrolled in a birth cohort study $(N=5,249)$, representing over $99 \%$ of all deliveries in the city at that year [10]. Pelotas is a medium-sized Southern Brazilian city (population 340,000 inhabitants) located near the border with Argentina and Uruguay. Mothers were interviewed soon after delivery on socioeconomic, demographic, behavioral, gestational, and delivery characteristics and newborns were weighed using calibrated pediatric scales. Birth length was also measured, as well as gestational age using the Dubowitz method [11].

In 2004-2005, all cohort members were sought for a follow-up visit. Several strategies were used to guarantee high follow-up rates. A census of all schools in Pelotas was carried out and children born in 1993 were linked with their cohort identification number. In addition, a census of all 100,000 households in the city was carried out in the search of children born in 1993. Again, those located were linked with their cohort identification number. Other strategies were used for the few children not located using these two strategies. Deaths were monitored using official mortality statistics. The incidence of fractures was investigated, as well as the anatomic site of the fracture and the age of the cohort member when it happened. During the face-to-face interview, the mothers were asked these questions as the adolescents were less likely to accurately remember early life fractures.

Data were entered twice with automatic checks for consistency and range. Analyses were carried out using Stata 9.0. After descriptive analyses, the incidence of fractures was calculated for each sub-group of the independent variables using the chi-square test for heterogeneity of linear trend. Incidence of fractures in each given age was calculated as the number of new cases divided by the total number of subjects. Multivariable analyses were performed using Logistic and Poisson regression, following a hierarchical framework defined a priori, as suggested previously [12]. The distal level included sex, family income and schooling. The intermediate level included maternal BMI, smoking, and age. The proximal level included birth weight, length, and gestational age. The effect of each independent variable on the outcome was adjusted for other covariates in the same level or above in the hierarchical model [12]. In the logistic models, the lifetime incidence of fractures (yes/no) were used as the outcome variable, while in the Poisson regression, the number of fractures reported $(0,1,2,3,4)$ was used.

The Ethical Committee of the Federal University of Pelotas Medical School approved the study protocol and written informed consents were obtained from parents or guardians.

\section{Results}

Out of the 5,249 participants of the cohort, 141 were known to have died before the 2004-2005 follow-up visit. Overall, 4,452 cohort members were located in this visit, resulting in a follow-up rate of $87.5 \%$. Table 1 presents follow-up rates according to key baseline characteristics. Follow-up rates did not vary according to sex and birth weight, but were slightly higher among adolescents belonging to the poorest families, born to mothers from the intermediate schooling groups, and who were obese. Although statistically significant, these differences in terms of follow-up rates were small. At least $79.9 \%$ of the cohort members were traced regardless of the sub-group.

Out of the 4,452 adolescents interviewed $29(0.7 \%)$ had missing values for the fracture-related variables and thus analyses of the outcome variable used a maximum of 4,423 data points. The lifetime incidence of fractures was $14.2 \%$ $(95 \% \mathrm{CI} 13.2,15.2)$. Out of the 628 subjects who experienced a fracture, 91 reported two fractures during lifetime and only 20 reported three or more fractures. There were 739 fractures among cohort members until the 2004 2005 follow-up visit. Table 2 presents the distribution of these fractures according to the anatomic site fractured.

Table 3 shows the incidence of fractures according to age. There was a direct association between incidence of fractures and age $(P<0.001)$. From birth to 5 years of age, the incidence of fractures was below $1 \%$ a year. Between 5 and 8 years, it ranged from $1.20 \%$ to $1.47 \%$. From 9 years of age onwards, the incidence of fractures was markedly increased (reaching more than $2 \%$ per year). 
Table 1 Follow-up rates at 11 years according to key baseline characteristics
${ }^{\text {a } I n c l u d i n g} 141$ deaths

${ }^{\mathrm{b}}$ Chi-square test

\begin{tabular}{|c|c|c|c|}
\hline Variable & Original cohort (number and \%) & $\%$ located $^{a}$ & $P$ value $^{\mathrm{b}}$ \\
\hline Sex & & & 0.18 \\
\hline Boys & $2,580(49.2 \%)$ & 86.9 & \\
\hline Girls & $2,667(50.8 \%)$ & 88.1 & \\
\hline Family income (minimum wages) & & & $<0.001$ \\
\hline$\leq 1$ & $967(18.4 \%)$ & 88.3 & \\
\hline $1.1-3.0$ & $2,260(43.1 \%)$ & 88.7 & \\
\hline $3.1-6.0$ & $1,204(22.9 \%)$ & 88.9 & \\
\hline $6.1-10.0$ & $433(8.3 \%)$ & 79.9 & \\
\hline$>10.0$ & $385(7.3 \%)$ & 82.6 & \\
\hline Maternal schooling at birth (years) & & & $<0.001$ \\
\hline 0 & $134(2.6 \%)$ & 82.1 & \\
\hline $1-4$ & $1,338(25.5 \%)$ & 88.7 & \\
\hline $5-8$ & $2,424(46.2 \%)$ & 89.9 & \\
\hline$\geq 9$ & $1,350(25.7 \%)$ & 82.5 & \\
\hline Birth weight $(\mathrm{g})$ & & & 0.16 \\
\hline$<2,500$ & $510(9.8 \%)$ & 89.8 & \\
\hline $2,500-3,499$ & $3,361(64.2 \%)$ & 86.9 & \\
\hline$\geq 3,500$ & $1,361(26.0 \%)$ & 87.9 & \\
\hline Pre-pregnancy body mass index & & & 0.004 \\
\hline$<20.0 \mathrm{~kg} / \mathrm{m}^{2}$ & $1,147(22.5 \%)$ & 87.6 & \\
\hline $20.0-24.9 \mathrm{~kg} / \mathrm{m}^{2}$ & $2,811(55.2 \%)$ & 86.6 & \\
\hline $25.0-29.9 \mathrm{~kg} / \mathrm{m}^{2}$ & $894(17.5 \%)$ & 90.3 & \\
\hline$\geq 30 \mathrm{~kg} / \mathrm{m}^{2}$ & $245(4.8 \%)$ & 92.2 & \\
\hline Overall & $5,249(100.0 \%)$ & 87.5 & \\
\hline
\end{tabular}

Table 4 presents the unadjusted and adjusted association between the independent variables and the history of fractures. Girls were $36 \%$ less likely than boys to experience a fracture. Both socioeconomic indicators analyzed (family income and maternal schooling) were

Table 2 Anatomic sites of the fractures in the 1993 Pelotas (Brazil) Birth Cohort Study

\begin{tabular}{lc}
\hline Anatomic site & Absolute frequency \\
\hline Arm and forearm & 332 \\
Fingers (foot and hand) & 94 \\
Clavicle & 64 \\
Leg & 58 \\
Wrist & 53 \\
Nose & 19 \\
Ankle & 15 \\
Elbow & 15 \\
Head & 11 \\
Ribs & 7 \\
Knee & 6 \\
Others or unspecified & $65^{\mathrm{a}}$ \\
\hline
\end{tabular}

ancludes 35 subjects who reported "foot" and seven who reported "hand". not associated with the incidence of fractures. Prepregnancy body mass index was also unrelated to the risk of fractures, as well as maternal smoking during pregnancy. High maternal age at delivery was a significant risk factor for fractures in both analyses (unadjusted and adjusted). Gestational age was not associated with the risk of fractures. Birth weight tended to be positively associated with the risk of fractures, although the difference was not

Table 3 Incidence of fractures according to age in the 1993 Pelotas (Brazil) Birth Cohort Study

\begin{tabular}{lc}
\hline Age (years) & Incidence of fractures $(\boldsymbol{N})$ \\
\hline $0-0.9$ & $0.61 \%(27)$ \\
$1-1.9$ & $0.54 \%(24)$ \\
$2-2.9$ & $0.70 \%(31)$ \\
$3-3.9$ & $0.84 \%(37)$ \\
$4-4.9$ & $0.84 \%(37)$ \\
$5-5.9$ & $1.20 \%(53)$ \\
$6-6.9$ & $1.27 \%(56)$ \\
$7-7.9$ & $1.15 \%(51)$ \\
$8-8.9$ & $1.47 \%(65)$ \\
$9-9.9$ & $2.15 \%(95)$ \\
$10-10.9$ & $2.44 \%(108)$ \\
\hline
\end{tabular}


Table 4 Incidence of fractures (yes/no), unadjusted and adjusted odds ratios according to the independent variables

\begin{tabular}{|c|c|c|c|c|c|}
\hline \multirow[t]{2}{*}{ Variable } & \multirow[b]{2}{*}{$\begin{array}{l}\text { Lifetime incidence of fractures } \\
(95 \% \mathrm{CI})\end{array}$} & \multicolumn{2}{|c|}{ Unadjusted analysis } & \multicolumn{2}{|l|}{ Adjusted analysis } \\
\hline & & $\begin{array}{l}\text { Odds ratio } \\
(95 \% \mathrm{CI})\end{array}$ & $P$ value & $\begin{array}{l}\text { Odds ratio } \\
(95 \% \mathrm{CI})\end{array}$ & $P$ value \\
\hline Sex & & & $<0.001^{\mathrm{a}}$ & & $<0.001^{\mathrm{a}}$ \\
\hline Boys & $17.0 \%(15.4 ; 18.5)$ & 1.00 & & 1.00 & \\
\hline Girls & $11.6 \%(10.2 ; 12.9)$ & $0.64(0.54 ; 0.76)$ & & $0.64(0.54 ; 0.76)$ & \\
\hline Family income at birth (minimum wages) & & & $0.17^{\mathrm{b}}$ & & $0.18^{\mathrm{b}}$ \\
\hline$\leq 1$ & $14.6 \%(12.2 ; 17.1)$ & $0.94(0.65 ; 1.35)$ & & $0.94(0.65 ; 1.36)$ & \\
\hline $1.1-3.0$ & $13.1 \%(11.5 ; 14.5)$ & $0.82(0.59 ; 1.15)$ & & $0.82(0.59 ; 1.15)$ & \\
\hline $3.1-6.0$ & $14.5 \%(12.3 ; 16.6)$ & $0.93(0.65 ; 1.32)$ & & $0.93(0.66 ; 1.33)$ & \\
\hline $6.1-10.0$ & $17.9 \%(13.7 ; 21.8)$ & $1.19(0.79 ; 1.80)$ & & $1.17(0.77 ; 1.78)$ & \\
\hline$>10.0$ & $15.4 \%(11.4 ; 19.5)$ & 1.00 & & 1.00 & \\
\hline Maternal schooling at birth (years) & & & $0.92^{\mathrm{b}}$ & & $0.41^{\mathrm{b}}$ \\
\hline 0 & $15.2 \%(8.0 ; 22.3)$ & 1.00 & & 1.00 & \\
\hline $1-4$ & $14.4 \%(12.3 ; 16.5)$ & $0.94(0.53 ; 1.67)$ & & $0.92(0.52 ; 1.63)$ & \\
\hline $5-8$ & $13.8 \%(12.3 ; 15.3)$ & $0.90(0.51 ; 1.58)$ & & $0.84(0.48 ; 1.48)$ & \\
\hline$\geq 9$ & $14.6 \%(12.5 ; 16.7)$ & $0.95(0.54 ; 1.70)$ & & $0.84(0.47 ; 1.52)$ & \\
\hline Pre-pregnancy body mass index & & & $0.10^{\mathrm{b}}$ & & $0.71^{\mathrm{b}}$ \\
\hline$<20.0 \mathrm{~kg} / \mathrm{m}^{2}$ & $15.7 \%(13.4 ; 17.9)$ & 1.00 & & 1.00 & \\
\hline $20.0-24.9 \mathrm{~kg} / \mathrm{m}^{2}$ & $13.4 \%(12.0 ; 14.8)$ & $0.84(0.68 ; 1.03)$ & & $0.83(0.67 ; 1.02)$ & \\
\hline $25.0-29.9 \mathrm{~kg} / \mathrm{m}^{2}$ & $13.3 \%(10.9 ; 15.7)$ & $0.83(0.63 ; 1.08)$ & & $0.81(0.62 ; 1.07)$ & \\
\hline$\geq 30 \mathrm{~kg} / \mathrm{m}^{2}$ & $18.2 \%(13.0 ; 23.3)$ & $1.20(0.82 ; 1.76)$ & & $1.15(0.78 ; 1.70)$ & \\
\hline Maternal smoking during pregnancy & & & $0.25^{\mathrm{a}}$ & & $0.17^{\mathrm{a}}$ \\
\hline No & $13.8 \%(12.5 ; 15.0)$ & 1.00 & & 1.00 & \\
\hline Yes & $15.1 \%(13.2 ; 16.9)$ & $1.11(0.93 ; 1.33)$ & & $1.13(0.95 ; 1.36)$ & \\
\hline Maternal age at delivery (years) & & & $0.02^{\mathrm{b}}$ & & $0.008^{\mathrm{b}}$ \\
\hline$<20$ & $11.8 \%(9.5 ; 14.1)$ & 1.00 & & 1.00 & \\
\hline $20-34$ & $14.3 \%(13.0 ; 15.5)$ & $1.24(0.97 ; 1.58)$ & & $1.23(0.96 ; 1.57)$ & \\
\hline$\geq 35$ & $17.5 \%(14.1 ; 20.8)$ & $1.58(1.15 ; 2.17)$ & & $1.55(1.12 ; 2.15)$ & \\
\hline Gestational age (weeks) & & & $0.25^{\mathrm{b}}$ & & $0.24^{\mathrm{b}}$ \\
\hline$<37$ & $12.5 \%(9.0 ; 16.0)$ & 1.00 & & 1.00 & \\
\hline $37-38.9$ & $13.7 \%(12.3 ; 15.1)$ & $1.12(0.79 ; 1.57)$ & & $1.04(0.72 ; 1.21)$ & \\
\hline$\geq 39$ & $15.2 \%(13.5 ; 16.8)$ & $1.26(0.89 ; 1.78)$ & & $1.16(0.79 ; 1.68)$ & \\
\hline Birth weight (g) & & & $0.08^{\mathrm{b}}$ & & $0.12^{\mathrm{b}}$ \\
\hline$<2,500$ & $10.8 \%(7.8 ; 13.9)$ & 1.00 & & 1.00 & \\
\hline $2,500-3,499$ & $14.1 \%(12.8 ; 15.4)$ & $1.35(0.97 ; 1.89)$ & & $1.35(0.97 ; 1.89)$ & \\
\hline$\geq 3,500$ & $15.4 \%(13.3 ; 17.4)$ & $1.49(1.05 ; 2.13)$ & & $1.42(0.99 ; 2.03)$ & \\
\hline Birth length (cm) & & & $0.002^{\mathrm{b}}$ & & $0.03^{\mathrm{b}}$ \\
\hline$\leq 46$ & $9.9 \%(7.4 ; 12.3)$ & 1.00 & & 1.00 & \\
\hline $46.1-48.0$ & $14.0 \%(12.0 ; 16.0)$ & $1.49(1.07 ; 2.06)$ & & $1.56(1.11 ; 2.21)$ & \\
\hline $48.1-50.0$ & $14.9 \%(13.2 ; 16.6)$ & $1.61(1.18 ; 2.19)$ & & $1.70(1.18 ; 2.45)$ & \\
\hline$>50.0$ & $15.8 \%(13.5 ; 18.1)$ & $1.72(1.24 ; 2.38)$ & & $1.80(1.16 ; 2.80)$ & \\
\hline
\end{tabular}

${ }^{a}$ Likelihood ratio test for heterogeneity

${ }^{\mathrm{b}}$ Likelihood ratio test for linear trend

statistically significant $(P=0.08$ in the unadjusted and $P=0.12$ in the adjusted analysis). Birth length was positively associated with the risk of fractures, both in the unadjusted and in the adjusted analyses. Those born taller than $50 \mathrm{~cm}$ were $80 \%$ more likely to experience a fracture in infancy or childhood than those born shorter than $46 \mathrm{~cm}$. Because parity could explain the higher risk of fractures among adolescents born to older mothers, we repeated the analyses including adjustment for this variable. The odds ratio of 1.55 for adolescents born to mothers aged 35 years 
Table 5 Poisson regression using number of fractures as the outcome variable

\begin{tabular}{|c|c|c|c|}
\hline \multirow{2}{*}{$\begin{array}{l}\text { Table } 5 \text { Poisson regression us- } \\
\text { ing number of fractures as the } \\
\text { outcome variable }\end{array}$} & Variable & Prevalence ratio $(95 \% \mathrm{CI})$ & $P$ value \\
\hline & Sex & & $<0.001^{\mathrm{a}}$ \\
\hline & Boys & 1.00 & \\
\hline & Girls & $0.73(0.63 ; 0.84)$ & \\
\hline & Family income at birth (minimum wages) & & $0.04^{\mathrm{b}}$ \\
\hline & $\leq 1$ & $0.80(0.60 ; 1.09)$ & \\
\hline & $1.1-3.0$ & $0.77(0.59 ; 1.01)$ & \\
\hline & $3.1-6.0$ & $0.86(0.66 ; 1.15)$ & \\
\hline & $6.1-10.0$ & $0.94(0.67 ; 1.83)$ & \\
\hline & $>10.0$ & 1.00 & \\
\hline & Maternal schooling at birth (years) & & $0.80^{\mathrm{b}}$ \\
\hline & 0 & 1.00 & \\
\hline & $1-4$ & $1.00(0.60 ; 1.67)$ & \\
\hline & $5-8$ & $0.95(0.57 ; 1.57)$ & \\
\hline & $\geq 9$ & $0.98(0.58 ; 1.65)$ & \\
\hline & Pre-pregnancy body mass index & & $0.81^{\mathrm{b}}$ \\
\hline & $<20.0 \mathrm{~kg} / \mathrm{m}^{2}$ & 1.00 & \\
\hline & $20.0-24.9 \mathrm{~kg} / \mathrm{m}^{2}$ & $0.88(0.73 ; 1.05)$ & \\
\hline & $25.0-29.9 \mathrm{~kg} / \mathrm{m}^{2}$ & $0.86(0.68 ; 1.09)$ & \\
\hline & $\geq 30 \mathrm{~kg} / \mathrm{m}^{2}$ & $1.12(0.81 ; 1.56)$ & \\
\hline & Maternal smoking during pregnancy & & $0.31^{\mathrm{a}}$ \\
\hline & No & 1.00 & \\
\hline & Yes & $1.08(0.93 ; 1.26)$ & \\
\hline & Maternal age at delivery (years) & & $0.008^{\mathrm{b}}$ \\
\hline & $<20$ & 1.00 & \\
\hline & $20-34$ & $1.22(0.99 ; 1.51)$ & \\
\hline & $\geq 35$ & $1.45(1.10 ; 1.92)$ & \\
\hline & Gestational age (weeks) & & $0.48^{\mathrm{b}}$ \\
\hline & $<37$ & 1.00 & \\
\hline & $37-38.9$ & $0.94(0.68 ; 1.29)$ & \\
\hline & $\geq 39$ & $1.01(0.73 ; 1.40)$ & \\
\hline & Birth weight $(\mathrm{g})$ & & $0.59^{\mathrm{b}}$ \\
\hline & $<2,500$ & 1.00 & \\
\hline & $2,500-3,499$ & $1.10(0.79 ; 1.54)$ & \\
\hline & $\geq 3,500$ & $1.01(0.68 ; 1.49)$ & \\
\hline & Birth length $(\mathrm{cm})$ & & $0.02^{\mathrm{b}}$ \\
\hline & $\leq 46$ & 1.00 & \\
\hline & $46.1-48.0$ & $1.35(1.02 ; 1.79)$ & \\
\hline & $48.1-50.0$ & $1.44(1.10 ; 1.88)$ & \\
\hline "Wald test for heterogeneity & $>50.0$ & $1.46(1.10 ; 1.94)$ & \\
\hline
\end{tabular}

${ }^{\text {a }}$ Wald test for heterogeneity

${ }^{\mathrm{b}}$ Wald test for linear trend or more found without such an adjustment was reduced to 1.49 when parity was adjusted for, thus suggesting no relevant confounding effect.

The multivariable analysis was repeated (Table 5) using the number of fractures $(0,1,2,3)$ as the outcome variable in a Poisson regression model. Risk factors were consistent with those presented in the logistic regression using a dichotomous variable (yes/no).

\section{Discussion}

To our knowledge, this is one of the few prospective studies evaluating the association between early life factors and risk of fractures from birth to adolescence. No previous studies on this issue were carried out in Latin America. Such studies are warranted because of the growing scientific interest in the Developmental Origins of Health 
and Disease (DOHaD) hypothesis, which suggest that preand post-natal variables operating in the first years of life may program health in the long term [13]. Initially focused on complex chronic disease indicators only, the DOHaD hypothesis has been expanded to mental health [14] and some researchers have suggested that musculoskeletal disorders could also be partially programmed by factors operating in early life $[15,16]$.

A previous study in Brazil found that $28.3 \%$ of the adults interviewed (aged 20 years or more) experienced at least one fracture during lifetime [17]. Consistently with that study, our analysis including adolescents showed that males were more likely than females to experience fractures. This trend is likely to be inverted with increasing age, when osteoporotic fractures, which are more frequent among women, start to happen. In the ALSPAC cohort in England [18], 8.9\% of the children experienced a fracture between 9.9 and 11.9 years of age. In our cohort, incidence of fractures between 9 and 10.9 years was $4.6 \%$. In the birth-to-twenty cohort from South Africa [19], 27.5\% of the participants sustained a fracture over a 15 -year period, compared to $14.2 \%$ over an 11-year period in our cohort.

In a New Zealand cohort, Jones and coworkers [8] found that birth length was positively associated with the risk of pre-pubertal fractures, which is in accordance to our results. A possible biological mechanism is the previously reported positive association between birth length and bone mineral density [18]. The negative findings of our study are also relevant in terms of public health. As observed in the New Zealand cohort [8], maternal smoking during pregnancy was not associated with the risk of fractures, although the New Zealand study found a positive association between adolescents' smoking and risk of fractures.

The positive association between maternal age and risk of fractures is difficult to interpret. Our original hypothesis was that children of adolescent mothers might have been at greater risk due to inadequate child care, but the results came out in the opposite direction. It is possible that older mothers have faced increased demands on calcium and vitamin D stores through repeated pregnancies, which could explain the positive association between maternal age and risk of fractures. However, adjustment for parity did not influence such an association. We found no other studies reporting such an association and confirmation by other researchers is essential.

A previous study in the same city reported that adults in the lowest socioeconomic position category-based on household assets-were 3.2 times more likely than those in the highest category to have experienced a fracture within the 12 months prior to the interview [17]. Because the socioeconomic classification is based on assets acquired over several years rather than concurrent income, reverse causality is unlikely to explain this finding. Data from the
ALSPAC cohort in the United Kingdom showed that social position is directly related to bone mineral content of adolescents [18], which may reduce their risk of fractures. These trends were not confirmed in our study with Brazilian adolescents. In the Poisson models, the association was actually in the opposite direction.

A limitation of our study is that, so far, we have no data on bone mineral density for cohort members. We are planning to collect such data in the next follow-up visit, which will take place in 2011, when subjects will be aged 18 years. An advantage of our study is that two multivariable techniques provided consistent results in terms of the risk factors for fractures, reducing the possibility of type 1 error. Also, the prospective nature of the data reduces the possibility of recall bias.

Our findings are in agreement with the literature regarding an increased risk of fractures among boys and among children who were longer at birth $[8,18,19]$. The finding on higher risk among children born to older mothers needs to be replicated. Our results suggest that, in accordance with the hypothesis of developmental origins of diseases, fractures seem to be, at least in part, programmed in early life.

Acknowledgements This analysis was supported by the Wellcome Trust initiative entitled Major Awards for Latin America on Health Consequences of Population Change. Earlier phases of the 1993 cohort study were funded by the European Union, the National Program for Centers of Excellence (Brazil), the National Research Council (Brazil) and the Ministry of Health (Brazil).

Conflicts of interest None.

Open Access This article is distributed under the terms of the Creative Commons Attribution Noncommercial License which permits any noncommercial use, distribution, and reproduction in any medium, provided the original author(s) and source are credited.

\section{References}

1. Jones IE, Williams SM, Dow N, Goulding A (2002) How many children remain fracture-free during growth? A longitudinal study of children and adolescents participating in the Dunedin Multidisciplinary Health and Development Study. Osteoporos Int 13:990-995

2. Kypri K, Chalmers DJ, Langley JD, Wright CS (2001) Child injury morbidity in New Zealand, 1987-1996. J Paediatr Child Health 37:227-234

3. Gelber AC, Hochberg MC, Mead LA, Wang NY, Wigley FM, Klag MJ (2000) Joint injury in young adults and risk for subsequent knee and hip osteoarthritis. Ann Intern Med 133:321-328

4. Yuan PS, Pring ME, Gaynor TP, Mubarak SJ, Newton PO (2004) Compartment syndrome following intramedullary fixation of pediatric forearm fractures. J Pediatr Orthop 24:370-375

5. Donaldson LJ, Cook A, Thomson RG (1990) Incidence of fractures in a geographically defined population. J Epidemiol Community Health 44:241-245 
6. Heaney RP, Abrams S, Dawson-Hughes B, Looker A, Marcus R, Matkovic V, Weaver C (2000) Peak bone mass. Osteoporos Int 11:985-1009

7. Johansen A, Evans RJ, Stone MD, Richmond PW, Lo SV, Woodhouse KW (1997) Fracture incidence in England and Wales: a study based on the population of Cardiff. Injury 28:655-660

8. Jones IE, Williams SM, Goulding A (2004) Associations of birth weight and length, childhood size, and smoking with bone fractures during growth: evidence from a birth cohort study. Am J Epidemiol 159:343-350

9. Harpham T, Huttly S, Wilson I, de Wet T (2003) Linking public issues with private troubles: panel studies in developing countries. J Int Dev 15:353-363

10. Victora CG, Hallal PC, Araujo CL, Menezes AM, Wells JC, Barros FC (2008) Cohort profile: the 1993 Pelotas (Brazil) birth cohort study. Int J epidemiol 37:704-709

11. Dubowitz L (1969) Assessment of gestational age in newborn: a practical scoring system. Arch Dis Child 44:782

12. Victora CG, Huttly SR, Fuchs SC, Olinto MT (1997) The role of conceptual frameworks in epidemiological analysis: a hierarchical approach. Int J epidemiol 26:224-227
13. Barker DJ (1990) The fetal and infant origins of adult disease. BMJ (Clinical research ed) 301:1111

14. Swanson JD, Wadhwa PM (2008) Developmental origins of child mental health disorders. J Child Psychol Psychiatry Allied Discipl 49:1009-1019

15. Cooper C, Javaid MK, Taylor P, Walker-Bone K, Dennison E, Arden N (2002) The fetal origins of osteoporotic fracture. Calcif Tissue Int 70:391-394

16. Jones G, Dwyer T (2000) Birth weight, birth length, and bone density in prepubertal children: evidence for an association that may be mediated by genetic factors. Calcif Tissue Int 67:304308

17. Siqueira FV, Facchini LA, Hallal PC (2005) The burden of fractures in Brazil: a population-based study. Bone 37:261266

18. Clark EM, Ness AR, Bishop NJ, Tobias JH (2006) Association between bone mass and fractures in children: a prospective cohort study. J Bone Miner Res 21:1489-1495

19. Thandrayen K, Norris SA, Pettifor JM (2009) Fracture rates in urban South African children of different ethnic origins: the birth to twenty cohort. Osteoporos Int 20:47-52 